\title{
Gyms and Martial Arts School after COVID-19: When to Come Back to Train?
}

\author{
Carlos Aurelio Andreucci ${ }^{1,2}$ \\ ${ }^{1}$ APCD, Sao Paulo, Brasil \\ ${ }^{2}$ Academia Jiu Jitsu, Sao Paulo, Brasil \\ Email: candreucci@hotmail.com
}

How to cite this paper: Andreucci, C. A, (2020). Gyms and Martial Arts School after COVID-19: When to Come Back to Train? Advances in Physical Education, 10, 114-120. https://doi.org/10.4236/ape.2020.102011

Received: April 8, 2020

Accepted: May 9, 2020

Published: May 12, 2020

Copyright $\odot 2020$ by author(s) and Scientific Research Publishing Inc. This work is licensed under the Creative Commons Attribution International License (CC BY 4.0).

http://creativecommons.org/licenses/by/4.0/

\begin{abstract}
To determine with safety when and how to open gyms after the COVID-19 epidemic, it's very important since almost all places are locked down and probably will be closed for a while or permanently. We need to keep studying options and the ways to do it, therefore the sooner we discuss it, the less damage there will be, especially for owners and professionals. This article reviews systematically all numbers available about coronavirus until 01 April 2020. Until this date, COVID-19 is affecting 203 countries and territories around the world and 2 international conveyances: the Diamond Princess Cruise ship harbored in Yokohama, Japan, and Holland America's MS Zaandam cruise ship. Objective: To determine when will be the right moment for gyms to come back and open their doors safely and how to prevent contamination of high risk people with COVID-19 in those places, directly and indirectly. Discussion: Well-known ways to help stop the spread of infection through personal hygiene, and adequate disinfection associated to social distancing, are reported in most articles about infection preventions, which are shown to be useful measures in SARS-COVID 2 also known as COVID-19. Conclusions: Private lessons are the best options after COVID-19, with control of body temperature before each class, a high level of personal hygiene and mat and equipment disinfection between classes for all activities in a gym. In group classes or closed spaces with more than 10 people, maintain 1 meter of distance if possible, using masks and gloves all the time until we have a better understanding of this virus's mutation. If possible and available, test coaches and instructors for COVID-19 every 14 days, the average period of incubation.
\end{abstract}

\section{Keywords}

COVID-19, SARS-COVID 2, Quarantine, Martial Arts, Gym 


\section{Introduction}

Social distancing and avoiding contact to control the risks of contamination of the new mutation of Corona Virus (SARS-COVID 2) are very difficult in Martial arts and change the routine in every Gym (Jefferson et al., 2011). Since this is associated with a high level of hygiene and disinfection, and they are the majority of procedures made in all countries with high numbers of infected people to prevent contamination (WHO, 2020a), finding a secure system to apply at gyms and martial arts academies is fundamental for those places to prevent people from getting infected, keeping their good health through exercises under professional supervision, and maintain the business at the lowest level of operation as soon as possible due to economic collapse and already foreseeable bankruptcy (IMC, 2020).

\section{Discussion}

Getting data about this new virus (SARS-CoV-2) is the only way to find solutions to prevent contamination and treat infected people. As the pandemic is still happening, we need to find safe measures as soon as possible to avoid having many people infected at the same time, so that we can also avoid overwhelming our healthcare systems (WHO, 2020b).

Since we know that exercise with professional supervision and balanced nutrition (with fruits and vegetables) are helpers to maintaining a good immune system (Palmowski, Boßlau, Ryl, Krüger, \& Reichel, 2019), it's very important to discuss the ways that allow people to get back to gyms and martial arts academies as soon as possible. This in turn helps to prevent the negative social, physical and mental health consequences associated with sedentarism due to quarantine.

The incubation period (time from exposure to the development of symptoms, Table 1) of the virus is estimated to be between 2 and 14 days (Imperial College London, 2020).

The symptoms (Table 2) seem to start with a fever, followed by a dry cough. After a week, it can lead to shortness of breath, with about $20 \%$ of patients requiring hospital treatment (WHO, 2020b).

There is evidence that human-to-human transmission has occurred among close contacts since the middle of December 2019. Considerable efforts to reduce transmission will be required to control outbreaks if similar dynamics apply elsewhere. Measures to prevent or reduce transmission should be implemented in populations at risk (Mandl, 2020).

The attack rate or transmissibility (how rapidly the disease spreads) of a virus is indicated by its reproductive number (Ro, pronounced $R$-nought or $r$-zero), which represents the average number of people to which a single infected person will transmit the virus. Preliminary studies had estimated Ro to be between 1.5 and 3.5. An outbreak with a reproductive number of below 1 will gradually disappear. For comparison, the Ro for the common flu is 1.3 and for SARS it was 2.0 (Mandl, 2020).

Globally, about 3.4\% of reported COVID-19 cases have died (Table 3 and Table 4). By comparison, seasonal flu generally kills far less than $1 \%$ of those 
Table 1. Report of the WHO-China Joint Mission on Coronavirus Disease 2019 (COVID-19) [Pdf] —World Health Organization, Feb. 28, 2020.

\begin{tabular}{cc}
\hline Virus & Incubation Period (typical cases) \\
\hline Novel Coronavirus (COVID-19) & $2-14$ or $0-24$ days ${ }^{*}$ \\
SARS & $2-7$ days, as long as 10 days \\
MERS & 5 days (range: $2-14)$ \\
Swine Flu & $1-4$ days, as long as 7 days \\
Seasonal Flu & 2 days $(1-4$ range $)$ \\
\hline
\end{tabular}

Table 2. Clinical characteristics of 138 hospitalized patients with 2019 novel coronavirus-infected pneumonia in Wuhan, China-JAMA, Wang et al., February 7, 2020.

\begin{tabular}{cc}
\hline \multicolumn{2}{c}{ Common symptoms included: (Wang et al., study) } \\
\hline Fever & $98.6 \%$ \\
Fatigue & $69.6 \%$ \\
Dry cough & $59.4 \%$ \\
\hline
\end{tabular}

Table 3. National Health Commission (NHC) of the People's Republic of China. Health Commission of Hubei Province, China, 04/01/2020.

\begin{tabular}{l}
\hline Currently Infected \\
\hline 655,755 \\
Mild Condition \\
$\mathbf{6 2 1 , 9 7 8}(95 \%)$ \\
Serious or Critical \\
$\mathbf{3 3 , 7 7 7}(5 \%)$ \\
\hline Table 4. National Health Commission (NHC) of the People's Republic of \\
China. Health Commission of Hubei Province, China, 04/01/2020. \\
\hline Cases with Outcome \\
$\mathbf{2 2 9 , 4 1 6}$ \\
Recovered/Discharged \\
$\mathbf{1 8 5 , 2 0 8}(81 \%)$ \\
Deaths \\
$\mathbf{4 4 , 2 0 8}(19 \%)$
\end{tabular}

infected, fatality rate for SARS was 10\%, and for MERS 34\% (Table 5). Every year an estimated 290,000 to 650,000 people die in the world due to complications from seasonal influenza (flu) viruses. This figure corresponds to 795 to 1781 deaths per day due to the seasonal flu (Wong, Kelly, Ip, Wu, Leung, \& Cowling, 2013).

Probability of dying infected by the virus depends on the age group (Table 6). Children from zero to nine years old have no cases of death. People under 39 
years old have $0.2 \%$ chance. Adults from 40 to 49 have $0.4 \%$. The highest ratio is among people over 80 years old, $14.8 \%$ followed by $70 \%$ to $79.08 \%$ (Wang et al., 2020).

Probability of dying if infected by the virus depends on pre-existing condition (Table 7). The cardiovascular disease represents $10.5 \%$, diabetes $7.3 \%$, chronic respiratory disease $6.3 \%$, hypertension $6 \%$, cancer $5.6 \%$ and no pre-existing conditions $0.9 \%$ (Wang et al., 2020).

Table 5. Report of the WHO-China Joint Mission on Coronavirus Disease 2019 (COVID-19) [Pdf]-World Health Organization, Feb. 28, 2020.

\begin{tabular}{cc}
\hline Virus & Death Rate \\
\hline Wuhan Novel Coronavirus $(2019-\mathrm{nCoV})$ & $2 \%^{*}$ \\
SARS & $9.6 \%$ \\
MERS & $34 \%$ \\
Swine Flu & $0.02 \%$ \\
\hline
\end{tabular}

Table 6. WHO-China Joint Mission published on Feb. 28 by WHO (WHO, 2020c) which are based on 55,924 laboratory confirmed cases. The report notes that "The Joint Mission acknowledges the known challenges and biases of reporting crude CFR early in an epidemic”.

\begin{tabular}{ccc}
\hline AGE & DEATH RATE confirmed cases & DEATH RATE all cases \\
\hline $80+$ years old & $21.9 \%$ & $14.8 \%$ \\
$70-79$ years old & $8.0 \%$ \\
$60-69$ years old & $3.6 \%$ \\
$50-59$ years old & $1.3 \%$ \\
$40-49$ years old & $0.4 \%$ \\
$30-39$ years old & $0.2 \%$ \\
$20-29$ years old & $0.2 \%$ \\
$10-19$ years old & $0.2 \%$ \\
0 - 9 years old & no fatalities \\
\hline
\end{tabular}

Table 7. WHO-China Joint Mission published on Feb. 28 by WHO (WHO, 2020c) which are based on 55,924 laboratory confirmed cases. The report notes that "The Joint Mission acknowledges the known challenges and biases of reporting crude CFR early in an epidemic".

\begin{tabular}{ccc}
\hline PRE-EXISTING CONDITION & $\begin{array}{c}\text { DEATH RATE } \\
\text { confirmed cases }\end{array}$ & $\begin{array}{c}\text { DEATH RATE } \\
\text { all cases }\end{array}$ \\
Cardiovascular disease & $13.2 \%$ & $10.5 \%$ \\
Diabetes & $9.2 \%$ & $7.3 \%$ \\
Hypertension & $8.0 \%$ & $6.3 \%$ \\
Cancer & $8.4 \%$ & $6.0 \%$ \\
no pre-existing conditions & $7.6 \%$ & $5.6 \%$ \\
\hline
\end{tabular}


The majority of people training martial arts are under 50 years old. Most above this age are teachers and instructors. At gyms the numbers are 25 to 54 years old with the average age of gym members being around 40 years old (IHRSA, 2010).

Every gym must measure the temperature of all students before entering the place, and all workers must use masks and maintain high level of hygiene (WHO, 2020a). Anyone with high risk diseases or with symptoms, needs to stay at home. Healthy people over 50 years old should not come back to Gym and martial arts until we better understand the disease. In these cases private lessons could be a solution, talk with your physician (IHME, 2020).

Temperature and humidity have proven helpful in avoiding or spreading the virus. Keeping open spaces and or temperature over 22 degrees Celsius (71.6 F) and humidity between $50 \%-80 \%$ have shown better results to lower risks for contamination (Moriyama, Hugentobler, \& Iwasaki, 2020).

Every family should take the risk factors into consideration, especially about spreading the virus to people with higher risk of death at home. If safety solutions are available, there is a need of taking care and paying very close attention to every daily routine, analyzing symptoms and having a plan to apply for every situation (CDC, 2020).

If the risks are greater for you and those around you, stay at home.

In grappling martial arts, it is especially hard to avoid full contact. You need to treat yourself as someone at high risk of spreading the virus and take care of others, not only yourself. Drilling and training muscle memory are very beneficial and are also ways to stay safe, as well as keeping your reflexes at their highest possible level (Gundersen, 2016). Martial arts with striking and other sports could begin without direct contact, while using masks and high level of hygiene until further notice about the COVID-19 numbers, prevention and treatment (Imperial College London, 2020).

Gyms need to control the numbers of members in closed spaces at one time, while also using masks and maintaining 1 meter distance at every possible moment. Before and after training use high level of hygiene with disinfection. Don't allow people to come every day. One or maximum two days per week students can come to the gym; more people will be able to train, since the least amount of repeating people will be present at the same time. Open spaces are better than closed ones. Private lessons are the best and safest option (Wang, 2020).

When authorities announce that the quarantine is over or that it's safe to come back to train, wait 14 days to start training, respect all the risks of age and diseases, and come back taking care of yourself and the others. Any sign of fever, cough, fatigue or shortness of breath must avoid contact and speak with a health care professional of your city (CDC, 2020).

Beginning to open the gyms as soon as possible after quarantine with safety measures, will help us develop better ways to understand how to increase the prevention of contamination, and help people to stay healthy through exercises 
under supervision, as well as create more opportunities for academies and gyms to survive at least in a minimal economic condition, to pay their bills, to keep their jobs, which includes helping people to be healthy. That's the best way to avoid any disease.

\section{Conclusion}

Private lessons are the best option after COVID-19, with control of body and ambient temperatures before each class, and high level of personal hygiene and disinfection between classes for all activities in a gym. In group classes or closed spaces with more than 10 people, respect 1 meter distance if possible, using masks and gloves at all times. If possible and available, test coaches and instructors for COVID-19 every 14 days, which is the average period of incubation. When masks and or gloves are not an option like in Jiu Jitsu classes, try to reduce the number of training partners in each class and follow the previous tips. People over 50 must avoid coming back to train until we know more about this new Corona Virus. Practice exercise under professional supervision and eat fruits and vegetables to acquire a good immune system.

\section{Conflicts of Interest}

The author declares no conflicts of interest regarding the publication of this paper.

\section{References}

CDC (2020). CDC Confirms Person-to-Person Spread of New Coronavirus in the United States. Atlanta, GA: CDC Press Release.

Gundersen, K. (2016). Muscle Memory and a New Cellular Model for Muscle Atrophy and Hypertrophy. Journal of Experimental Biology, 219, 235-242.

https://doi.org/10.1242/jeb.124495

IHME (2020). IHME COVID-19 Health Service Utilization Forecasting Team. Forecasting COVID-19 Impact on Hospital Bed-Days, ICU-Days, Ventilator Days and Deaths by US State in the Next 4 Months. New York: MedRxiv.

IHRSA (2010). IHRSA Profiles of Success: The Annual Industry Data Survey of the Health and Fitness Club Industry. Boston, MA: The International Health, Racquet \& Sportsclub Association and Industry Insights, Inc.

IMC (2020). World Economic Outlook. Washington DC: International Monetary Fund.

Imperial College London (2020). Report 3: Transmissibility of 2019-nCoV. London: Imperial College London.

Jefferson, T. et al. (2011). Physical Interventions to Interrupt or Reduce the Spread of Respiratory Viruses. Roma: John Wiley \& Sons, Ltd. https://doi.org/10.1002/14651858.CD006207.pub3

Mandl, M. M. (2020). Early Transmissibility Assessment of a Novel Coronavirus in Wuhan, China. Cambridge, MA: Harvard University.

Moriyama, M., Hugentobler, W. J., \& Iwasaki, A. (2020). Seasonality of Respiratory Viral Infections. Annual Review of Virology, 7, 1-2.

https://doi.org/10.1146/annurev-virology-012420-022445 
Palmowski, J., Boßlau, T. K., Ryl, L., Krüger, K., \& Reichel, T. (2019). Managing Immune Health in Sports: A Practical Guide for Athletes and Coaches. German Journal of Sports Medicine, 70, 219-226. https://doi.org/10.5960/dzsm.2019.389

Wang, D. et al. (2020). Clinical Characteristics of 138 Hospitalized Patients with 2019 Novel Coronavirus-Infected Pneumonia in Wuhan, China. JAMA, 323, 1061-1069. https://doi.org/10.1001/jama.2020.1585

Wang, W. (2020). Updated Understanding of the Outbreak of 2019 Novel Coronavirus $(2019 \mathrm{nCoV})$ in Wuhan, China. Journal of Medical Virology. https://doi.org/10.1002/jmv.25689

WHO (2020a). COVID-19 Strategy Update. Geneva: WHO.

WHO (2020b). International Health Regulations Emergency Committee on Novel Coronavirus in China. Geneva: WHO.

WHO (2020c). Report of the WHO-China Joint Mission on Coronavirus Disease. Geneva: WHO.

Wong, J., Kelly, H., Ip, D. K., Wu, J., Leung, G., \& Cowling, B. (2013). Case Fatality Risk of Influenza A (H1N1pdm09): A Systematic Review. Epidemiology, 24, 830-841.

https://doi.org/10.1097/EDE.0b013e3182a67448 